\title{
Likelihood of adoption of arsenic-mitigation technologies under perceived risks to health, income, and social discrimination to arsenic contamination
}

\author{
S.K. Singh \& R.W. Taylor \\ Department of Earth and Environmental Studies, Montclair State University, Montclair, NJ, USA
}

\begin{abstract}
This study aims to assess the likelihood of adoption of arsenic-mitigation technologies under perceived risks in an Indian rural region that confronts severe and chronic groundwater arsenic contamination. A total of 340 households were surveyed in three arsenic-affected villages of Bihar, India. The average population perceives greater health risks and economic risks to arsenic-contaminated groundwater than social discrimination risk, therefore, are willing to adopt arsenic-mitigation technologies. Caste, education, income, sanitation practices, people's prioritization of socio-environmental problems, arsenic awareness, and social capital, were the strongest predictors of perceived economic risk. The same variables as above (with the exception of income, sanitation practices, and social capital) with additional factors like agricultural landholdings, and social trust, were the strongest predictors of perceived health risks. However, in the case of perceived social discrimination risk, the respondents' agricultural landholdings, people's prioritization of social problems, arsenic awareness, and social capital, were the strongest predictors.
\end{abstract}

\section{INTRODUCTION}

Risk perceptions play a vital role in the development of government policies and their subsequent adoption, as they significantly influence individuals' proclivities for hazards management that could affect human safety and health, or ecological conditions (Gerber and Neeley 2005). Until now the risk perception framework has been mostly applied in research related to climate change adaptations and natural hazards, and its application in decision-making for areas such as flood insurance, coastal environment protection, landslides, heat waves, chemical industries, air pollution and hurricanes is a recent phenomenon (Bickerstaff, 2004; Carlton and Jacobson, 2013; Damm et al., 2013; Huang et al., 2013; Jones et al., 2013; Peacock, et al., 2005; Tam and McDaniels, 2013). On the issue of groundwater contamination, there are only a handful of studies that have addressed the relationship between perceived risks of groundwater contamination and a significant increase in expenditures on activities aimed at mitigation (Abdalla, 1992; Janmaat, 2007). There are some studies that have applied the risk perception framework to water quality issues (Dupont and Krupnick, 2010; Jakus et al., 2009; McSpirit and Reid, 2011; Nguyen et al., 2010; Onjala et al., 2014; Walker et al., 2006). Studies of decision-making under perceived health risk are still in the rudimentary stage. We did not encounter any existing studies that have evaluated decision-making for better environmental services under perceived risks to income (economic risk) or risk of social discrimination.
Also, none of the studies has attempted to investigate the causal relationships between socioeconomic and demographic factors, knowledge and awareness, institutional trust, social capital, and social trust to risk perceptions in the context of arsenic-contamination. This study aims to address two primary goals related to the aforementioned gaps: a) to investigate people's decision-making to adopt arsenic-mitigation under perceived risks to health, income (economic), and social discrimination to arsenic; and b) to analyze the socioeconomic, demographic, and other factors that construct people's risk perception to groundwater arsenic-contamination.

\section{METHODS}

\subsection{Administration of the survey}

Based on the current levels of arsenic severity and the arsenic-mitigation initiatives, three villages, namely Suarmarwa, Rampur Diara, and Bhawani Tola of the Maner block of Patna district in Bihar, India were selected for this study (Singh, 2015; Singh et al., 2018) (Fig. 1). Detailed description of the survey administration, arsenic contamination, and socioeconomic models of arsenic mitigation are provided in other studies (Singh, 2015; Singh et al., 2016, 2017), in brief, the surveyed populations were randomly selected and stratified by the variable of caste, as the castes (forward, backward, and scheduled caste) are the sub-groups of the people in the project area, which are internally homogeneous, but externally heterogeneous (UNSD, 2008). 


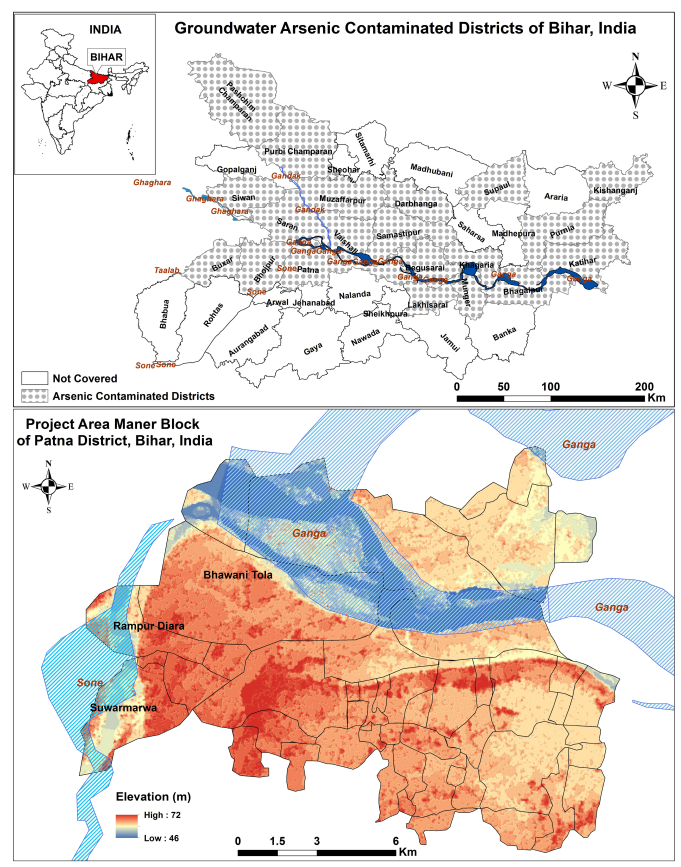

Figure 1. A map showing the arsenic affected districts of Bihar and the three villages selected for this study with their elevations (Singh et al., 2018).

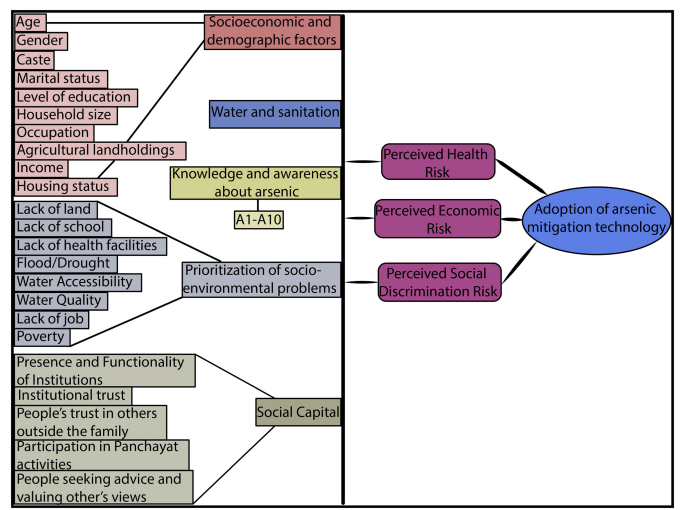

Figure 2. The conceptual framework of risk perception and decision-making of arsenic-mitigation technology.

\subsection{Conceptual framework of risk perception and decision-making of arsenic mitigation technology}

The arsenic risk perception model has been conceptualized based on the hypothesis that; a) the arsenicexposed communities will adopt arsenic-mitigation technologies or programs under perceived health risk; perceived economic risk; and perceived risk of social discrimination; and $\mathrm{b}$ ): the existing socioeconomic and demographic factors, people's prioritization of socio-environmental problems, and social capital, are significant drivers in constructing people's perceived risks (Fig. 2).
Table 1. Socioeconomic and demographic characteristics of the studied populations.

\begin{tabular}{|c|c|c|c|c|c|}
\hline & Variables & Suarmarwa & Rampur Diara & Bhawani Tola & $\mathrm{p}$-value \\
\hline \multirow{2}{*}{ Gender } & Female & 10 & 2 & 5 & \multirow[t]{2}{*}{0.038} \\
\hline & Male & 101 & 117 & 105 & \\
\hline \multirow{5}{*}{ Age group } & 18-28 & 9 & 15 & 8 & \multirow[t]{5}{*}{0.049} \\
\hline & $29-39$ & 16 & 27 & 21 & \\
\hline & $40-50$ & 36 & 28 & 36 & \\
\hline & \begin{tabular}{|l|}
$51-61$ \\
\end{tabular} & 23 & 18 & 12 & \\
\hline & 62 and above & 16 & 12 & 23 & \\
\hline \multirow{3}{*}{ Caste } & Scheduled caste & 23 & 19 & 20 & \multirow[t]{3}{*}{$<0.001$} \\
\hline & \begin{tabular}{|l|} 
Backward caste \\
\end{tabular} & 77 & 18 & 37 & \\
\hline & Forward caste & 0 & 62 & 43 & \\
\hline \multirow{2}{*}{ Marital status } & Single & 5 & 9 & 1 & \multirow[t]{2}{*}{0.015} \\
\hline & Married & 95 & 91 & 99 & \\
\hline \multirow{4}{*}{ Education level } & Illititerate & 49 & 11 & 14 & \multirow[t]{4}{*}{$<0.001$} \\
\hline & Primary education & 41 & 40 & 41 & \\
\hline & \begin{tabular}{|l|} 
Secondary education \\
\end{tabular} & 8 & 31 & 31 & \\
\hline & College & 1 & 18 & 14 & \\
\hline \multirow{3}{*}{ Household size } & $\leq 5$ & 43 & 36 & 34 & \multirow[t]{3}{*}{0.569} \\
\hline & $>5-10>$ & 51 & 56 & 61 & \\
\hline & $>10$ & 5 & 8 & 5 & \\
\hline \multirow{4}{*}{ Occupation } & Unemployed & 22 & 3 & 2 & \multirow{4}{*}{$<0.001$} \\
\hline & Labor & 51 & 30 & 35 & \\
\hline & \begin{tabular}{|l|} 
Agriculture \\
\end{tabular} & 20 & 41 & 39 & \\
\hline & Job + Business & 7 & 25 & 24 & \\
\hline \multirow{3}{*}{ Income group } & $\begin{array}{l}\text { BPL(Rs. } 500<\text { per } \\
\text { month) }\end{array}$ & 27 & 4 & 2 & \multirow[t]{3}{*}{$<0.001$} \\
\hline & \begin{tabular}{|l|} 
Lower \\
APL(>Rs.500- \\
Rs. 10,000 per \\
month) \\
\end{tabular} & 60 & 76 & 78 & \\
\hline & \begin{tabular}{|l|} 
Upper \\
APL $(>$ Rs. 10,000 \\
per month)
\end{tabular} & 13 & 20 & 20 & \\
\hline \multirow{2}{*}{ Agricultural landholdings } & \begin{tabular}{|l|} 
No landholdings \\
\end{tabular} & 48 & 65 & 55 & \multirow[t]{2}{*}{0.024} \\
\hline & Landholdings & 52 & 35 & 45 & \\
\hline \multirow{4}{*}{ Housing status } & Straw made & 19 & 7 & 3 & \multirow[t]{4}{*}{0.001} \\
\hline & Thatched roof & 29 & 21 & 24 & \\
\hline & Kachcha house & 30 & 39 & 44 & \\
\hline & Pucca house & 22 & 34 & 29 & \\
\hline
\end{tabular}

\subsection{Data analysis}

Statistical Package for Social Sciences (SPSS), IBM version 21 in Windows environment, was used for statistical analysis (IBM, 2012; SPSS, 2012). A bivariate analysis was performed between the risk perceptions (health, economic, and social discrimination) and socioeconomic, demographic and other variables (IBM, 2012; SPSS, 2012; Warner, 2012).

\section{RESULTS AND DISCUSSION}

\subsection{Socioeconomic and demographic characteristics of the surveyed population}

The detailed socioeconomic and demographic survey results are explained in (Singh, 2015), here we present a village-wise comparison of socioeconomic and demographic survey results that help to understand the socioeconomic and demographic characteristics of the surveyed population (Table 1).

\subsection{Perceived risks and decision-making for arsenic-mitigation technologies}

The vast majority of individuals (91\%) perceived health risk due to drinking arsenic-contaminated water 
Willingness to adopt arsenic mitigation technologies under various perceived risks

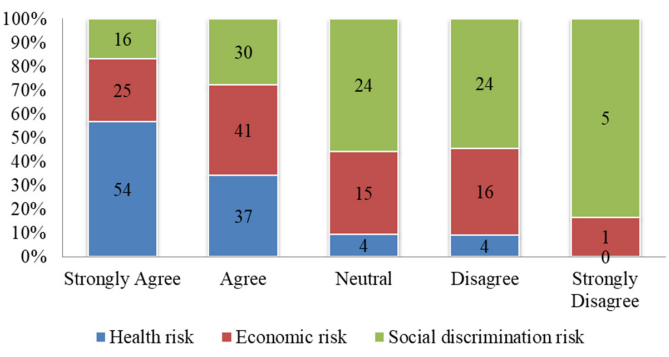

Figure 3. Participants' responses to statements on perceptions in the context of the adoption of arsenic mitigation options.

and was willing to adopt arsenic-mitigation technologies (Fig. 3).

About $66 \%$ of the respondents perceive economic risk from arsenic contamination. Only $46 \%$ of the surveyed population connects risk of social discrimination with arsenic contamination. The respondents showed a neutral response to perceived social discrimination risk, with the numbers almost equally split between those who perceive social discrimination risk and others who disagree or are neutral. The respondents of Rampur Diara village were slightly more likely $(93 \%)$ to adopt arsenic-mitigation under perceived health risk than the respondents of Suarmarwa $(90 \%)$ and Bhawani Tola (89\%) villages.

\subsection{Factors influencing likelihood of adoption of arsenic-mitigation technologies under perceived risks}

Variables such as caste, education level, agricultural landholdings, housing status, presence and functionality of Anganwadi, and social capital (people who participate in panchayat activities), were found to have a contributing effect on communities' perceived health risk. Moreover, people's perceived economic risk was found to be strongly positively correlated with the respondents' health risk perception. In sum, educated higher caste communities who own land, live in better housing structures, and had trust in Anganwadi $^{1}$ in the area, tend to perceive more health risk. Therefore, under perceived health risk, communities that possess the above mentioned characteristics will adopt arsenic mitigation technology in the arseniccontaminated areas (Table 2). The results of bivariate analyses showed that there was a very strong positive correlation between respondents' perceived health risk, social discrimination risk, and their perceived economic risk. It further shows that the communities that had high perceived health risk and social discrimination risk were likely to perceive more economic risk (Table 2).

\footnotetext{
${ }^{1}$ Anganwadi (courtyard shelter) is a government of India's child-care and mother-care unit at panchayat levels, comprised of mostly female health workers.
}

Table 2. Predictors of risk perceptions to health risk, economic risk, and social discrimination risk.

\begin{tabular}{|c|c|c|c|}
\hline & $\begin{array}{r}\text { Health risk } \\
\text { perception }\end{array}$ & $\begin{array}{r}\text { Economic } \\
\text { risk } \\
\text { perception }\end{array}$ & $\begin{array}{r}\text { Socia } \\
\text { discrimination risk } \\
\text { perception }\end{array}$ \\
\hline Caste & $.174^{* * 2}$ & $.242^{* 2}$ & -.062 \\
\hline Education level & $.111^{*}$ & $.184^{* *}$ & .102 \\
\hline Agricultural landholdings & $.156^{* *}$ & .047 & $-.127^{\circ}$ \\
\hline Housing status & $.112^{*}$ & $.124^{\prime \prime}$ & .036 \\
\hline Time spent for water collection & .059 & .093 & $-.171^{* *}$ \\
\hline Distance from water source & .057 & .065 & $-.120^{\circ}$ \\
\hline Place for defecation & .077 & $.170^{* *}$ & .082 \\
\hline $\begin{array}{r}\text { Materials used to wash hands after } \\
\text { defecation }\end{array}$ & .062 & $.162^{* *}$ & .082 \\
\hline Lack of land & .081 & $.184^{* *}$ & .017 \\
\hline Lack of school & .047 & $.265^{* *}$ & .072 \\
\hline Lack of health facilities & -.099 & $-.295^{* *}$ & -.093 \\
\hline Flood & -.035 & $-.122^{*}$ & -.016 \\
\hline Water accessibility & .046 & $-.158^{* *}$ & .071 \\
\hline Water quality & -.059 & $-.228^{* *}$ & .000 \\
\hline Poverty & .032 & $.325^{* *}$ & -.018 \\
\hline Arsenic awareness & .032 & $.234^{* *}$ & $.110^{\circ}$ \\
\hline $\begin{array}{r}\text { Opinion about the presence and } \\
\text { functionality of Anganwadi }\end{array}$ & $.139^{*}$ & $-.158^{* s}$ & -.058 \\
\hline $\begin{array}{l}\text { Opinion about the presence and } \\
\text { functionality of Mahila Samakhya }\end{array}$ & -.076 & -.042 & $-.197^{* 4}$ \\
\hline $\begin{array}{l}\text { Opinion about the presence and } \\
\text { functionality of Self Help Groups }\end{array}$ & .026 & .057 & $-.226^{* *}$ \\
\hline Trust in NGOS & .106 & $.161^{* *}$ & $.232^{*}$ \\
\hline Trust in Panchayat Raj Institutions & .039 & $.141^{* *}$ & $.251^{*}$ \\
\hline Trust in private agencies & -.018 & $.169^{* *}$ & .077 \\
\hline Participation in panchayat activities & $.107^{*}$ & .046 & .008 \\
\hline $\begin{array}{r}\text { Neighbors and others seek advice and } \\
\text { value views }\end{array}$ & .091 & $.397^{* *}$ & $.191^{*}$ \\
\hline Health risk perception & 1.000 & $.268^{* 8}$ & .068 \\
\hline Economic risk perception & $.268^{* *}$ & 1.000 & $.233^{* *}$ \\
\hline Social discrimination risk perception & .068 & $.233^{* *}$ & 1.000 \\
\hline
\end{tabular}

Likewise, a strong positive correlation was derived between caste, education level, housing status, sanitation behavior (place for defecation and material used to wash hands after defecation), people's prioritization of social problems (lack of land, lack of school, and poverty), arsenic awareness, trust in agencies (NGOs, Panchayati Raj Institutions, private agencies), and individual social capital, as neighbors and others sought and valued their advice, with the residents' perceived economic risk (Table 2). However, a strong negative correlation was observed between people's prioritization of socio-environmental problems (lack of health facilities, flood/drought, water accessibility, and water quality), and presence and functionality of institutions (Anganwadi), with the respondents' perceived economic risk.

In sum, socio-demographic factors (caste, education, and housing status), sanitation practice, people's prioritization of socio-environmental problems, arsenic awareness, presence and functionality of institution (Anganwadi), trust in agencies, and social capital, were found to be strong predictors of the perceived economic risk of the communities (Table 2). In comparison to the other two perceived risks (economic and health risks), we found fewer predictors of perceived risk of social discrimination. None of the socioeconomic and demographic factors, except agricultural landholdings, was found to be a statistically significant predictor of the communities' social risk perception. People with larger agricultural landholdings, who spent more time collecting water (and traveled a distance of $>50 \mathrm{~m}$ ), and the communities 
that had higher trust in Mahila Samakhya ${ }^{2}$ and SelfHelp Groups ${ }^{3}$ were strongly negatively correlated with their social discrimination risk perception. In contrast, those who were aware of arsenic contamination, who had trust in NGOs and Panchayati Raj Institutions, and the respondents with higher social capital were found to be strongly positively correlated with their perceived social discrimination risk. Furthermore, communities' social discrimination risk perception was found to be strongly positively correlated with their perceived economic risk (Table 2).

\section{CONCLUSIONS}

This study provides insights into communities' decision-making to adopt arsenic-mitigation technologies under their perceived risks to health, income, and social discrimination to groundwater arseniccontamination. The findings are potentially advantageous to policymakers, as this help identify the mechanisms of decision-making to adopt better environmental services for the communities' wellbeing. Risk perception in general, but health, economic and social discrimination risk perceptions in particular, cause individuals to take precautionary measures and support policies aimed at arsenic-mitigation (Botzen et al., 2009). A "one-size-fits-all" approach to promoting arsenic-mitigation is unlikely to succeed owing to the heterogeneous nature of the communities affected. As is evident from this paper, different castes and economic classes, constituting the affected communities, have differing perceptions of health, economic and social risk, because of their varied perceptions and priorities. Upper caste communities should be targeted for immediate arsenic-mitigation, as they are more likely to adopt. This might also help to enhance technology adoption among lower castes due to the fact that the latter seek to emulate the former in many situations. However, it appears that, unfortunately, health concerns take a backseat to pressing issues of economic survival for lower-caste and impoverished households. In the short-term, education and awareness campaigns aimed at arsenic contamination and, specifically, its adverse impacts on livelihoods should be implemented among the lower caste communities, including backward and scheduled caste. Communities with minimal trust in the institutions and low social capital, both owing perhaps to their social marginalization, were most concerned with economic risks and social discrimination risks. However, underprivileged communities for whom social problems were the highest priority had low or no arsenic awareness.

\footnotetext{
${ }^{2}$ The Mahila Samakhya is a women's empowerment program of the government of India, designed to aid socioeconomically impoverished women through increased literacy.

${ }^{3}$ Self Help Groups are comprised of socioeconomically disadvantaged women in villages in India and other South Asian countries primarily established for social empowerment through micro-finance.
}

Therefore, to raise arsenic awareness in these communities, campaigns should focus, in the medium to long-term, on strengthening institutions and enhancing social capital activities. Most importantly, these institutions should be involved in village level arsenic mitigation-programs. That groundwater arsenic may not be a priority among poor communities should not be seen as a discouraging finding. On the contrary, it should be seen as an affirmation of the fact that environmental and health perceptions are related to socioeconomic problems like lack of jobs, lack of land, lack of schools, or lack of health facilities. Understanding these linkages could be very useful for understanding how people perceive risks, what the predictors are, and how decisions are made for ultimately delivering better social or environmental services. The identified predictors of the three risk perceptions to groundwater arsenic-contamination will help us model the risk perceptions to arsenic-contamination. The results of this study suggest that severity of groundwater, soil, or food arsenic contamination, while important, should not be the only control on mitigation policies. People's risk perception plays a vital role in the adoption of arsenic-mitigation interventions. Caste, broad measures of economic well-being and markers of social status within the community are important drivers of the different risk perceptions. However, it appears that social marginality, which is a relative social position (as determined by the compounding effect of education, landholding, arsenic awareness, among other factors), is a crucial factor, perhaps more so than absolute measures of income and education. Therefore, socioeconomic and demographic factors, awareness, institutional trust, social trust, and social capital, etc., should necessarily be evaluated before implementing any arsenic-mitigation policy. This approach would help increase adoption of arsenic-mitigation interventions and achieve their sustainable use.

\section{REFERENCES}

Abdalla, C.W., Brian, A.R. \& Donald, J.E. 1992. Valuing environmental quality changes using averting expenditures: an application to groundwater contamination. Land Econ. 68(2): 163-169.

Bickerstaff, K. 2004. Risk perception research: socio-cultural perspectives on the public experience of air pollution. Environ. Int. 30(6): 827-840.

Botzen, W.J.W., Aerts, J.C.J.H. \& van den Bergh, J.C.J.M. 2009. Dependence of flood risk perceptions on socioeconomic and objective risk factors. Water Resour. Res. 45(10): 455-464.

Carlton, S.J. \& Jacobson, S.K. 2013. Climate change and coastal environmental risk perceptions in Florida. J. Environ. Manage. 130: 32-39.

Damm, A., Eberhard, K., Sendzimir, J. \& Patt, A. 2013. Perception of landslides risk and responsibility: a case study in eastern Styria, Austria. Nat. Hazards 69(1): 165-183.

Dupont, D. \& Krupnick, A. 2010. Differences in water consumption choices in Canada: the role of sociodemographics, experiences, and perceptions of health risks. J. Water Health 8(4): 671-686. 
Gerber, B.J. \& Neeley, G.W. 2005. Perceived risk and citizen preferences for governmental management of routine hazards. Policy Stud. J. 33(3): 395-418.

Huang, L., Ban, J., Sun, K., Han, Y.T., Yuan, Z.W. \& Bi, J. 2013. The influence of public perception on risk acceptance of the chemical industry and the assistance for risk communication. Safety Sci. 5 (1): 232-240.

IBM 2012. IBM SPSS statistics for Windows, version 21.0. IBM Corp Armonk, New York.

Jakus, P.M., Shaw, W.D., Nguyen, T.N. \& Walker, M. 2009. Risk perceptions of arsenic in tap water and consumption of bottled water. Water Resour. Res. 45(5).

Janmaat, J. 2007. Divergent drinking water perceptions in the Annapolis Valley. Can. Water Resour. J. 32(2): 99-110.

Jones, E.C., Faas, A.J., Murphy, A.D., Tobin, G.A., Whiteford, L.M. \& McCarty, C. 2013. Cross-cultural and site-based influences on demographic, well-being, and social network predictors of risk perception in hazard and disaster settings in Ecuador and Mexico. Human Nature 24(1): 5-32.

McSpirit, S. \& Reid, C. 2011. Residents' perceptions of tap water and decisions to purchase bottled water: a survey analysis from the Appalachian, Big Sandy Coal Mining Region of West Virginia. Soc. Natur. Resour. 24(5): 511-520.

Nguyen, T.N., Jakus, P.M., Riddel, M. \& Shaw, W.D. 2010. An empirical model of perceived mortality risks for selected US arsenic hot spots. Risk Anal. 30(10): 1550-1562.

Onjala, J., Ndiritu, S.W. \& Stage, J. 2014. Risk perception, choice of drinking water and water treatment: evidence from Kenyan towns. J. Water Sanit. Hyg. Dev. 4(2): 268-280.

Peacock, W.G., Brody, S.D. \& Highfield, W. 2005. Hurricane risk perceptions among Florida's single family homeowners. Landsc. Urban Plan. 73(2): 120-135.
Singh, S.K. 2015. Assessing and Mapping Vulnerability and Risk Perceptions to Groundwater Arsenic Contamination: Towards Developing Sustainable Arsenic Mitigation Models. Available from ProQuest Dissertations \& Theses Full Text. (1681668682). PhD Dissertation/Thesis, Earth and Environmental Studies, Montclair State University.

Singh, S.K., Brachfeld, S.A. \& Taylor, R.W. 2016. Evaluating hydrogeological and topographic controls on groundwater arsenic contamination in the Middle-Ganga plain in India: towards developing sustainable arsenic mitigation models. In: A. Fares (ed) Emerging Issues in Groundwater Resources. pp. 263-287.

Singh, S.K., Taylor, R.W. \& Su, H. 2017. Developing sustainable models of arsenic-mitigation technologies in the Middle-Ganga Plain in India. Curr. Sci. 113(1): 80-93.

Singh, S.K., Taylor, R.W., Rahman, M.M. \& Pradhan, B. 2018. Developing robust arsenic awareness prediction models using machine learning algorithms. J. Environ. Manage. 211: 125-137.

SPSS, IBM 2012. IBM SPSS Statistics Version 21. Boston, Mass. International Business Machines Corp.

Tam, J. \& McDaniels, T. L. 2013. Understanding individual risk perceptions and preferences for climate change adaptations in biological conservation. Environ Sci Policy 27: 114-123.

UNSD 2008. Designing household survey samples: practical guidelines. Vol. 98. USA: United Nations Statistical Division (UNSD).

Walker, M., Shaw, W.D. \& Benson, M. 2006. Arsenic consumption and health risk perceptions in a rural western US area. J. Am. Water Resour. Assoc. 42(5): 1363-1370.

Warner, R.M. 2012. Applied Statistics: From Bivariate Through multivariate Techniques. Sage Publications. 